University of Louisville

ThinkIR: The University of Louisville's Institutional Repository

$5-2018$

\title{
Intraoral imaging at insertion of implant supported restorations at an academic institution : conformity to established guidelines.
}

\author{
J. Alec Power \\ University of Louisville
}

Follow this and additional works at: https://ir.library.louisville.edu/etd

Part of the Other Dentistry Commons

\section{Recommended Citation}

Power, J. Alec, "Intraoral imaging at insertion of implant supported restorations at an academic institution : conformity to established guidelines." (2018). Electronic Theses and Dissertations. Paper 2914.

https://doi.org/10.18297/etd/2914

This Master's Thesis is brought to you for free and open access by ThinkIR: The University of Louisville's Institutional Repository. It has been accepted for inclusion in Electronic Theses and Dissertations by an authorized administrator of ThinkIR: The University of Louisville's Institutional Repository. This title appears here courtesy of the author, who has retained all other copyrights. For more information, please contact thinkir@louisville.edu. 


\title{
INTRAORAL IMAGING AT INSERTION OF IMPLANT SUPPORTED RESTORATIONS AT AN ACADEMIC INSTITUTION: CONFORMITY TO ESTABLISHED GUIDELINES
}

\author{
By \\ J. Alec Power \\ B.S., University of Michigan, 2012

\begin{abstract}
A Thesis
Submitted to the Faculty of the School of Dentistry of the University of Louisville in Partial Fulfillment of the Requirements for the Degree of
\end{abstract} \\ Master of Science in Oral Biology \\ Department of Oral Biology \\ University of Louisville School of Dentistry \\ Louisville, Kentucky
}

May, 2018 
Copyright 2018 by John Alexander Power

All rights reserved 



\section{INTRAORAL IMAGING AT INSERTION OF IMPLANT SUPPORTED RESTORATIONS AT AN ACADEMIC INSTITUTION: CONFORMITY TO ESTABLISHED GUIDELINES}

By

J. Alec Power

B.S., University of Michigan, 2012

A Thesis Approved on

May 6, 2018

By the following Thesis Committee

\begin{tabular}{l}
\hline Dr. William C. Scarfe \\
\hline Dr. Bruno Azevedo \\
\hline Dr. Michael J. Metz
\end{tabular}

Dr. Michael J. Metz 


\section{ACKNOWLEDGMENTS}

I would like to thank my family for their support and encouragement. I would like to thank my amazing wife Erin for her ceaseless support. I would also like to thank my mentor Dr. William Scarfe and the rest of my research committee for their gracious support and constant guidance. Their fine leadership is a true inspiration and is what I aspire to emulate in the field of dentistry.

This research was supported by a grant from the University of Louisville School of Medicine Summer Research Scholar Program. 


\begin{abstract}
INTRAORAL IMAGING AT INSERTION OF IMPLANT SUPPORTED RESTORATIONS AT AN ACADEMIC INSTITUTION: CONFORMITY TO ESTABLISHED GUIDELINES
\end{abstract}

J. Alec Power

May 6, 2018

The objective of this study was to establish the frequency of intraoral imaging at the time of insertion of implant supported restorations at University of Louisville School of Dentistry (ULSD). After IRB approval (14.1215), patients on whom an implantsupported single unit fixed restoration was placed were identified from the electronic health record over a 4-year period. Type of prosthesis retention (cement vs. screw) and discipline responsible for crown placement was recorded. Bitewing $(\mathrm{BWx})$ or periapical (pa) images taken at the time of prosthesis placement were accessed and reviewed. Overall radiographic frequency according to modality was tallied and compared using Chi-square ( $\mathrm{p} \leq 0.05) .269$ patients had 425 implants restored with single unit crowns (74\% cement retained, $26 \%$ screw retained). Only $61 \%$ (259) of implants had images taken at the time of prosthesis placement. More implants had a pa image (38\% [163]) than BWx image (23\% [96]) at the time of crown delivery $\left(X^{2}=42.03, p<0.0001\right) .25 \%$ (41) prosthesis insertions required more than one image at the time of placement, an average of 1.4 retakes per crown. Imaging rates varied significantly between specific disciplines $\left(\mathrm{X}^{2}=27.75, \mathrm{p}<0.0001\right)$ and ranged from $70.8 \%$ to $34.2 \%$. There was a 
significant difference in intraoral radiography between cement retained (65\%) and screw retained $(51 \%)$ groups $\left(\mathrm{X}^{2}=6.45, \mathrm{p}=0.01\right)$. More than $1 / 3^{\text {rd }}$ of implant supported restorations are not imaged at the time of insertion. Both BWx and pa radiography is used to image crown placement. A greater percentage of cement retained prosthesis were imaged at time of insertion compared to screw retained. Specific imaging protocols should be implemented across disciplines to standardize teaching strategies for clinical faculty and to ensure quality control. 
TABLE OF CONTENTS

PAGE

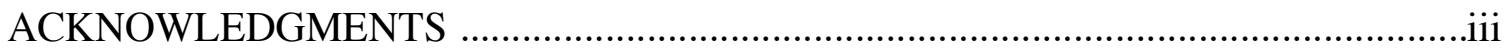

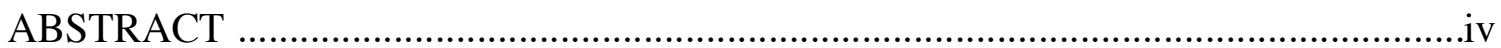

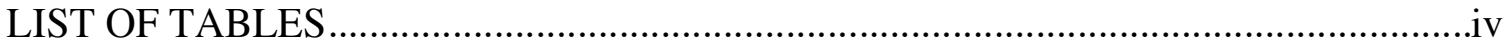

LIST OF FIGURES ................................................................................................

INTRODUCTION

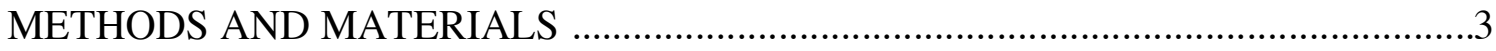

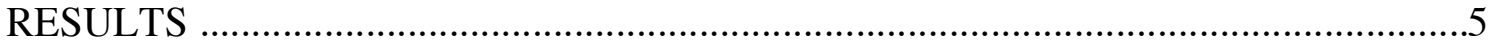

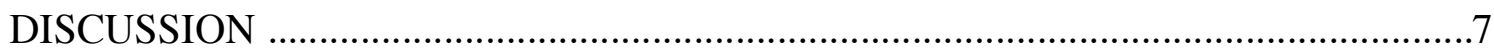

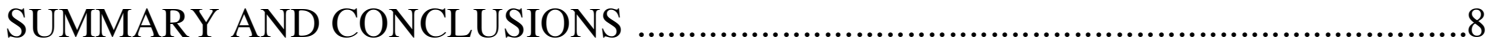

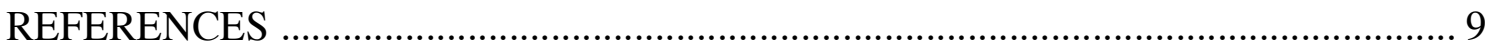

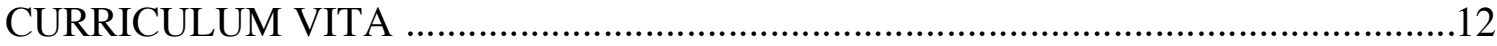




\section{LIST OF TABLES}

TABLE

PAGE

1. Immediate Post Prosthesis Insertion Intraoral Imaging Rates by Discipline and Imaging

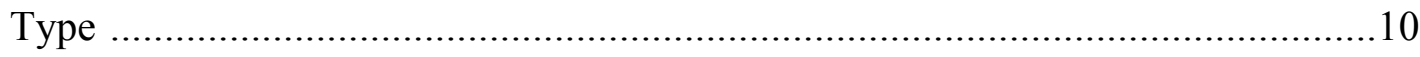

2. Immediate Post Prosthesis Insertion Intraoral Periapical Imaging Rates by Discipline.

3. Immediate Post Prosthesis Insertion Intraoral Bitewing Imaging Rates by Discipline.

4. Immediate Post Prosthesis Insertion Intraoral Imaging Rates (percentages) by

Retention Mechanism. ..................................................................... 12 


\section{LIST OF FIGURES}

$\begin{array}{lll}\text { FIGURE PAGE } & \text { PAR }\end{array}$

1. Examples of periapical and bitewing images taken at time of insertion of implant

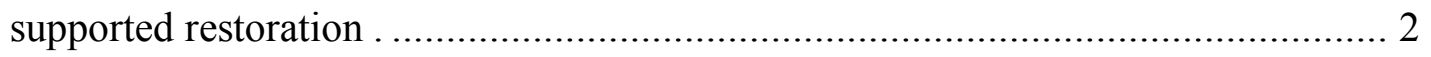




\section{INTRODUCTION}

Intraoral periapical imaging is an important diagnostic adjunct in the assessment of implants post-operatively. However, even in a controlled dental environment (single dental office), Rushton and Horner found that $30 \%$ to $50 \%$ of all intraoral dental images taken may be of poor or unacceptable diagnostic quality ${ }^{1}$. They also suggested that diagnostic image quality may be improved with undergraduate and continuing education for all members of the dental team with an emphasis on more practical hands-on instruction.

The prevalence of non-diagnostic images in post-operative implant assessment in research studies ranges from $13 \%{ }^{8}$ to $25 \%,{ }^{10}$ with an average of $13.3 \%{ }^{6}$. However, in a clinical environment, such as at an academic institution, the prevalence of non-diagnostic images has not been reported. Because treatment is often performed by multiple operators with variable experience and expertise in an academic institution, a greater prevalence of non-diagnostic images would be expected than reported in research studies. Nondiagnostic images provide uncertainty in post-operative assessment and can necessitate re-exposure of the patient. Analysis of the errors associated with non-diagnostic images for post-operative monitoring of dental implants may assist in identifying optimal techniques or protocols for use in an academic environment. Before the diagnostic quality of post-operative images of dental implants can be assessed, the frequency with which these images are taken and comparison to established imaging guidelines must first be 
determined. Current imaging guidelines suggest that intraoral radiography be performed at specific stages of dental implant treatment including surgical placement of the implant body, abutment insertion, prosthesis (crown) placement (Fig. 1) and periodically after completion or when symptomatic.

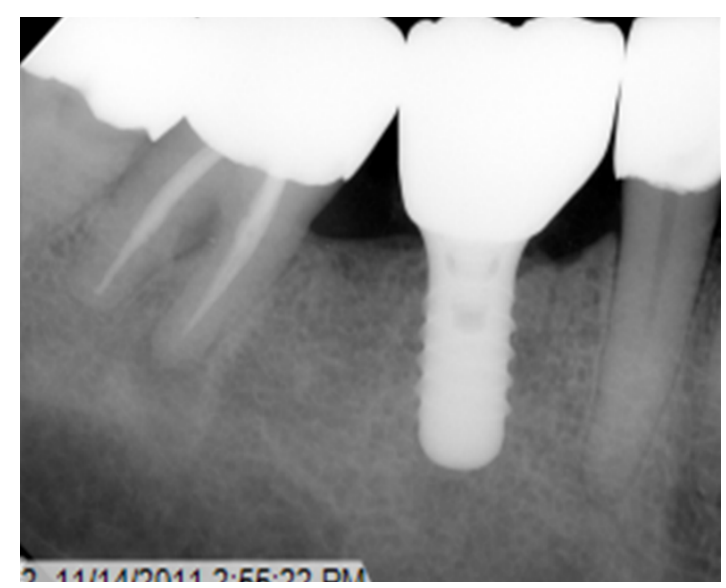

a

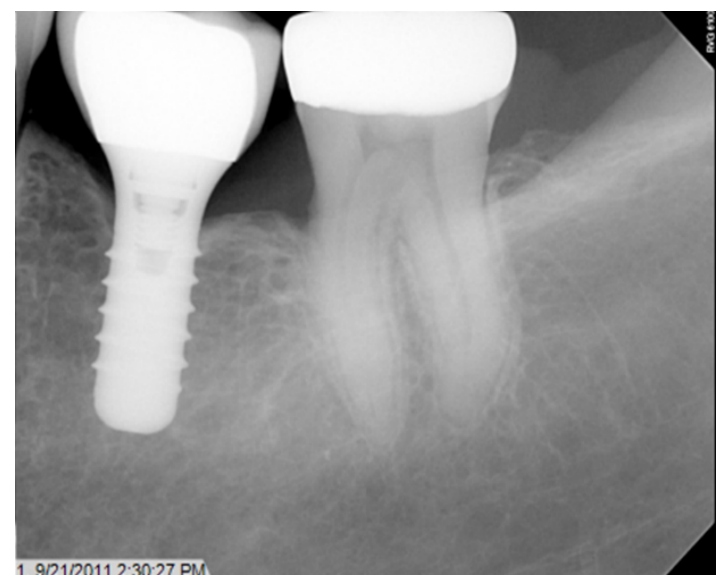

$\mathrm{c}$

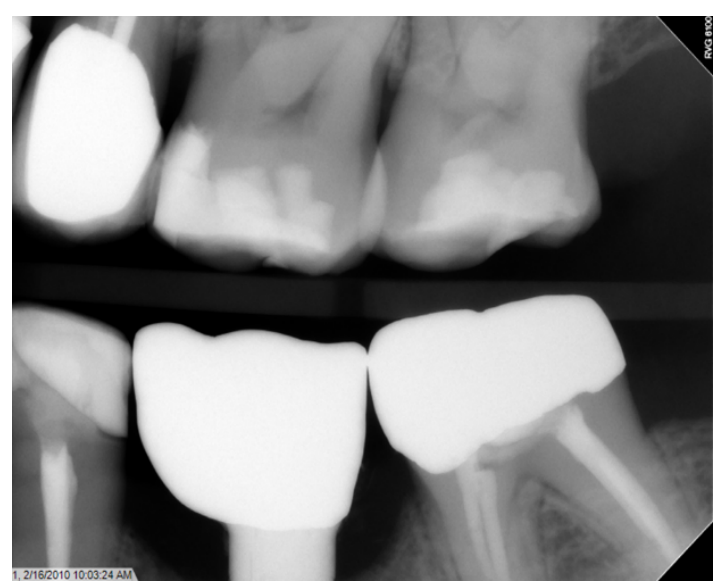

b

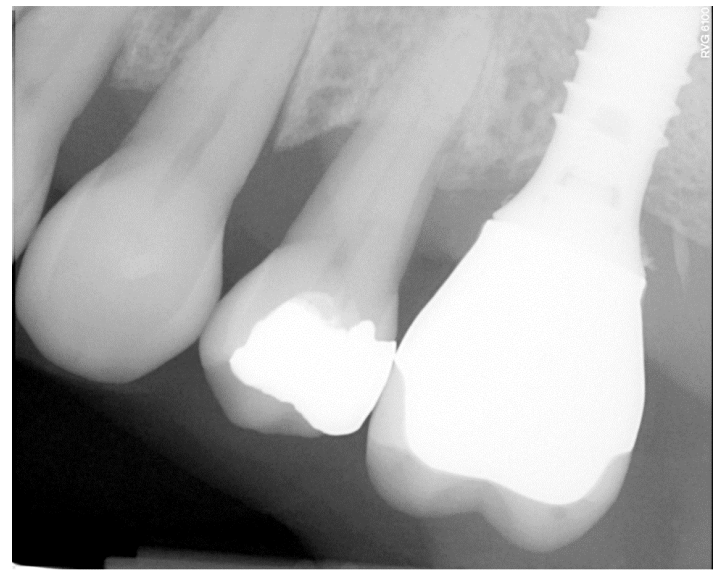

d

FIGURE 1. Examples of periapical and bitewing images taken at time of insertion of implant supported restoration: (a) right mandibular periapical image covering the entire crown and implant at tooth site $\# 29$, (b) right molar bitewing image showing only the crown of the implant at tooth site \#30 - this image is diagnostically unacceptable because 
it does not demonstrate the adjacent marginal alveolar bone, (c) left mandibular periapical image covering the entire crown and implant at tooth site \#19 and, (d) left maxillary periapical image covering the entire crown partially covering the implant at tooth site \#14. - note that there is cement residue on the distal aspect of the implant surface immediately below the abutment joint.

In this research study we focused on the prosthesis placement phase at the University of Louisville School of Dentistry (ULSD). It is recommended that periapical (pa) or bitewing (BWx) images be taken of the implant at the time of prosthesis placement. In order to determine if the proper imaging guidelines were being followed at The University of Louisville School of Dentistry, the frequency of post-operative images for implants at prosthesis placement was recorded for each area within the institution responsible for prosthesis delivery. 


\section{HYPOTHESES}

\section{Objectives}

The aims of this research are:

1. To establish the overall frequency of intraoral imaging (bitewing or periapical radiography) at the time of insertion of implant supported restorations at an academic institution (ULSD).

2. To compare the differences in the incidence of taking BWx and pa images at the time of insertion of implant supported restorations.

3. To compare the differences in the incidence of taking BWx and pa images at the time of insertion of implant supported restorations according to type of retention mechanism.

4. To compare the differences between individuals in various areas of responsibility at an academic institution (ULSD) in the incidence of taking images overall (BWx and pa) at the time of insertion of implant supported restorations

5. To compare the differences between individuals in various areas of responsibility at an academic institution (ULSD) in the incidence of taking BWx images at the time of insertion of implant supported restorations

6. To compare the differences between individuals in various areas of responsibility at an academic institution (ULSD) in the incidence of taking pa images at the time of insertion of implant supported restorations 


\section{Null Hypothesis}

It is hypothesized that:

1. There is no difference in the overall frequency of intraoral imaging (bitewing or periapical radiography) at the time of insertion of implant supported restorations at an academic institution (ULSD) as compared to the published recommendation for imaging (100\%).

2. There is no difference in the incidence of taking BWx and pa images at the time of insertion of implant supported restorations.

3. There is no difference in the incidence of taking BWx and pa images at the time of insertion of implant supported restorations according to type of retention mechanism.

4. There is no difference between individuals in various areas of responsibility at an academic institution (ULSD) in the incidence of taking images overall (BWx and pa) at the time of insertion of implant supported restorations

5. There is no difference between individuals in various areas of responsibility at an academic institution (ULSD) in the incidence of taking BWx images at the time of insertion of implant supported restorations

6. There is no difference between individuals in various areas of responsibility at an academic institution (ULSD) in the incidence of taking pa images at the time of insertion of implant supported restorations 


\section{METHODS}

\section{Sample}

The ULSD patient database (AxiUm) was searched for patients on whom a dental implant was placed over a 4-year period (1/1/2011-12/31/2014) (IRB approval 14.1215). Edentulous patients that have received multiple implants for implant-retained mandibular over-dentures or fixed dental prosthesis were excluded from the study as panoramic radiography is used for post-operative imaging in this cohort. The inclusion criteria consisted of patients who had a single unit endosteal dental implant inserted and whose implant was restored (American Dental Association [ADA] Common Procedural Code [CPT] D6058-D6067) by an operator(s) at ULSD.

\section{Data Collection and Analysis}

The following data concerning the operative procedure was extracted from the Axium records for each subject:

- Date the implant(s) placed,

- Discipline area of responsibility within ULSD who placed the implants

- Undergraduate program (DMD student)

- Dental student supervised by faculty in the Department of Oral Health and Rehabilitation (OHR) 
- Dental student supervised by faculty in the comprehensive care clinic (DMD),

- Resident in Advanced Dental Specialty program

- Periodontics (PERIO)

- Prosthodontics (PROS)

- General Practice Residency (GPR),

$\circ$ Faculty Private Practice (FPP)

- Information regarding the implant(s) placed.

- Number, size, location, and brand of implant

- Date the restoration(s) was placed,

- Who placed the restoration,

- Type of retention mechanism

- screw or cement

This information was used to help determine exactly which type of operator performed the images at each step in the post-operative implant monitoring process.

Next, the digital picture archiving and communications system (MiPACS) was accessed on dates corresponding to the prosthesis placement stage of dental implant therapy (CPT codes [D6058 - D6067]) to determine if imaging was performed. For each date associated with restoration insertion the following information regarding the intraoral imaging was extracted from the MiPACS database:

- Presence of absence of imaging taken at time of insertion

- Type of imaging procedure performed

$\circ$ Bitewing (BWx) 


\section{- Periapical (pa)}

- Total Number of images taken at time of prosthesis delivery

- Was the image of acceptable diagnostic quality? Image quality was deemed acceptable if the image was added to the radiographic template.

Overall and image frequency according to radiographic modality (BWx or pa) was tallied according the individual's discipline area and compared using Chi-square $(\mathrm{p} \leq$ $0.05)$ 


\section{RESULTS}

\section{Sample}

There were a total of 269 patients who were anonymously identified by an Axium database Boolean "and" search query using the American Dental Association (ADA) CPT treatment codes related to the implant procedures. Within this cohort, 425 implants were placed between October 2007 and February 2015. Patients were between the ages of 21 years to 85 years with an average age of 57 years. $43 \%$ of patients were male and $57 \%$ were female.

\section{Descriptive Statistics}

Table 1 summarizes the intraoral imaging rates per discipline and type of imaging procedure.

The average overall image completion rate (BWx and pa) across all disciplines was $61 \% .38 \%(n=163)$ of implants had a periapical image and $22.3 \%(n=96)$ had BWx image taken at the time of crown insertion. Among the 163 implants with pa images associated with them, 222 pa images were required to obtain images of acceptable diagnostic quality. $25 \%$ (41) required more than 1 pa image to be taken of the same implant to obtain an acceptable image. This comes to an average of 1.4 pa images taken 
per implant crown. Additionally, there were 13 implants that required 3 or more pa images to obtain a diagnostically acceptable image.

TABLE 1. Immediate Post Prosthesis Insertion Intraoral Imaging Rates by Discipline and Imaging Type

\section{Crowns with imaging}

\begin{tabular}{lcccccc} 
& & & & & $\begin{array}{c}\text { Crowns } \\
\text { without } \\
\text { imaging }\end{array}$ & $\begin{array}{c}\text { Total \# } \text { of } \\
\text { crowns } \\
\text { inserted }\end{array}$ \\
\hline OHR & 31 & 66 & 97 & $71 \%$ & 40 & $137(32 \%)$ \\
DMD & 41 & 52 & 93 & $70 \%$ & 39 & $132(31 \%)$ \\
FPP & 18 & 15 & 33 & $50 \%$ & 33 & $66(16 \%)$ \\
PERIO & 0 & 17 & 17 & $46 \%$ & 20 & $37(9 \%)$ \\
PROS & 2 & 10 & 12 & $34 \%$ & 23 & $35(8 \%)$ \\
GPR & 4 & 3 & 7 & $39 \%$ & 11 & $18(4 \%)$ \\
\hline Total & $\mathbf{9 6}$ & $\mathbf{1 6 3}$ & $\mathbf{2 5 9}$ & $\mathbf{6 1 \%}$ & $\mathbf{1 6 6}$ & $\mathbf{4 2 5}(\mathbf{1 0 0 \% )}$ \\
\hline
\end{tabular}

OHR, Oral Health and Rehabilitation Advanced Prosthodontics; DMD, DMD Clinic; FPP, Faculty private practice; PERIO, Graduate Periodontal Clinic; PROS, Graduate Prosthodontics Clinic; GPR, General practice residency;

Statistical difference between disciplines, ${ }^{1}\left(\chi^{2}\right.$ yates correction $\left.=19.91, \mathrm{p}=0.0013\right),{ }^{2}\left(\chi^{2}\right.$ yates correction $=15.74, \mathrm{p}=0.0076),{ }^{3}\left(\chi^{2}\right.$ yates correction $\left.=27.75, \mathrm{p}<0.0001\right)$

Comparing the overall rates of imaging at the time of insertion of implant supported restorations, dental students (OHR and DMD) performed radiography more frequently ( $71 \%$ and $70 \%$ respectively) than any other discipline including FPP, PERIO, PROS and GPR $(\chi 2$ Yates correction $=27.75, \mathrm{p}<0.0001)$. Comparing the rates of BWx 
and pa imaging at the time of insertion of implant supported restorations according to discipline, pa images were taken more often (38.4\%) than BWx images $(22.5 \%)$ ( $\chi 2$ yates correction $=42.034, \mathrm{p}<0.0001)$.

Table 2 and 3 shows the overall rates of pa and BWX imaging respectively at the time of insertion of implant supported restorations according to discipline

TABLE 2. Immediate Post Prosthesis Insertion Intraoral Periapical Imaging Rates by Discipline

\begin{tabular}{lccc}
\hline Discipline & pa image taken & No pa image taken & Total \\
\hline OHR & $66(48.2 \%)$ & 71 & 137 \\
DMD & $52(39.4 \%)$ & 80 & 132 \\
FPP & $15(22.7 \%)$ & 51 & 66 \\
PERIO & $17(48.6 \%)$ & 20 & 37 \\
PROS & $10(28.6 \%)$ & 25 & 35 \\
GPR & $3(16.6 \%)$ & 15 & 18 \\
\hline Total & $\mathbf{1 6 3}$ & $\mathbf{2 6 2}$ & $\mathbf{4 2 5}$ \\
\hline
\end{tabular}

$\chi^{2}$ Yates correction $=15.74, p=0.0076$

Comparing the overall rates of periapical imaging at the time of insertion of implant supported restorations, DMD students supervised by OHR faculty and PERIO performed periapical radiography more frequently than any other discipline ( $\chi 2$ Yates correction $=15.74, \mathrm{p}=0.0076)$ 
TABLE 3. Immediate Post Prosthesis Insertion Intraoral Bitewing Imaging Rates by Discipline

\begin{tabular}{lccc}
\hline Discipline & BW $\boldsymbol{x}$ image taken & No BW image taken & Total \\
\hline OHR & $31(22.6 \%)$ & 106 & 137 \\
DMD & $41(31.1)$ & 91 & 132 \\
FPP & $18(27.3 \%)$ & 48 & 66 \\
PERIO & $0(0 \%)$ & 37 & 37 \\
PROS & $2(5.7 \%)$ & 33 & 35 \\
GPR & $4(22.2 \%)$ & 14 & 18 \\
\hline Total & 96 & 329 & 425 \\
\hline
\end{tabular}

$\chi 2$ Yates correction $=19.91, \mathrm{p}=0.0013$

Comparing the overall rates of BWx imaging at the time of insertion of implant supported restorations, DMD students supervised in the comprehensive care clinic and FPP performed BWx radiography more frequently than any other discipline ( $\chi 2$ Yates correction $=19.91, \mathrm{p}=0.0013)$

Table 4 shows the frequency of overall imaging at the time of implant prosthesis insertion according to type of retention mechanism.

TABLE 4. Immediate Post Prosthesis Insertion Intraoral Imaging Rates (percentages) by Retention Mechanism

\begin{tabular}{lccc}
\hline $\begin{array}{l}\text { Retention } \\
\text { Mechanism }\end{array}$ & $\begin{array}{c}\text { Image taken }(B W X \\
\text { and pa) }\end{array}$ & No image taken & Total \\
\hline Cement & $202(78 \%)$ & $111(64.8 \%)$ & $313(74 \%)$ \\
Screw & $57(22 \%)$ & $55(35.2 \%)$ & $112(26 \%)$ \\
\hline Total & $\mathbf{2 5 9}(\mathbf{6 0 . 9 \%})$ & $\mathbf{1 6 6}(\mathbf{3 9 . 1 \%})$ & $\mathbf{4 2 5}$ \\
\hline
\end{tabular}


Statistical difference between disciplines $\chi^{2}$ Yates correction $=5.89, \mathrm{p}=0.015$

Out of the 425 implants restored, $74 \%$ of all implant crowns were cement retained, with the remaining $26 \%$ being screw retained. Significantly more cementretained restorations $(64.5 \%)$ were imaged at the time of crown insertion as compared to screw retained $(50.9 \%)(\chi 2$ Yates correction $=5.89, \mathrm{p}=0.015)$ 


\section{DISCUSSION}

The results of this study demonstrate that at a specific institutional setting (ULSD), approximately $1 / 3 \mathrm{rd}$ of implants are not imaged at the time of single prosthesis insertion and thus poor compliance with clinical guidelines recommending intraoral imaging be performed at the time of crown placement. While higher compliance was found with cement retained prostheses $(78 \%)$, this is still markedly below the standard found to be necessary in the literature. Post operative imaging of cement retained prostheses is particularly important to identify the presence of remaining cement which has been shown to be associated with peri-implant inflammation and bleeding.

Amongst disciplines, we expected the highest rates of imaging or highest conformity to established guidelines to be associated with the graduate level providers. However we found the contrary to be true - we the highest incidence of imaging performed by predoctoral dental students supervised by faculty from the Dept. of Oral Health and Rehabilitation or faculty in the comprehensive care clinics. This is counterintuitive in that one might expect that more experience clinicians should confirm to guidelines. However, it appears that at least in our Institutional setting, increased supervision is required to improve conformity.

The results of this study also indicate that in many cases multiple retakes were required to obtain radiographic images that the clinician deemed clinically acceptable. 
With an average of 1.4 intraoral images required per crown insertion, patients are being exposed to unnecessary radiation to obtain desired images.

Periapical radiography seems to be the preferred technique for imaging implants at the prosthesis insertion stage. However, there seems to be some preference of operators in specific disciplines (FPP and GPR) to favor BWX. This suggests that there is some confusion in discipline specific areas on which imaging technique is optimal for the assessment of dental implants and the crown immediately post insertion.

It is obvious that in our institution there is a need for education of all clinicians on the need for imaging at the time of implant prosthesis insertion, particularly those in advanced specialty programs. In addition, there is also a need to improve intraoral radiographic technique as applied to implant imaging, standardize the imaging technique used (BWx or pa) and establish imaging radiography guidelines. 


\section{CONCLUSION}

Overall, there was poor compliance at our Institution with current clinical guidelines recommending intraoral imaging be performed of dental implants at the time of crown placement. There is no consistent use of intraoral technique for post insertion imaging. These results suggest the importance of future studies into frequency of imaging compliance at each stage of dental implant treatment. Also, further investigation into the diagnostic quality of these intraoral images is indicated based on the higher number of retakes reported. With further investigations, we can hope to solve these problems at an academic institution with the implementation of additional radiographic technique training and imaging protocols. 


\section{REFERENCES}

1. Rushton V.E., Horner K. The impact of quality control on radiography in general dental practice. Br Dent J. 1995 Oct 7;179(7):254-61.

2. Laurell L, Lundgren D. Marginal bone level changes at dental implants after 5 years in function: a meta-analysis. Clin Implant Dent Relat Res 2011: 13: 19-28.

3. Riecke, B., Friedrich, R. E., Schulze, D., Loos, C., Blessmann, M., Heiland, M., \& Wikner, J. (2014). Impact of malpositioning on panoramic radiography in implant dentistry. Clin Oral Investig. doi: 10.1007/s00784-014-1295-1

4. Personal communication, Dr. Bryan Harris, Dept of Prosthodontics, ULSD

5. Vandeweghe S, Cosyn J, Thevissen E, van den Berghe L, De Bruyn H. A 1-year prospective study on co-axis implants immediately loaded with a full ceramic crown. Clin Implant Dent Relat Res 2012: (Suppl. 1): e126-e138.

6. Harris, D., Horner, K., Grondahl, K., Jacobs, R., Helmrot, E., Benic, G. I., . . Quirynen, M. (2012). E.A.O. guidelines for the use of diagnostic imaging in implant dentistry 2011. A consensus workshop organized by the European Association for Osseointegration at the Medical University of Warsaw. Clin Oral Implants Res, 23(11), 1243-1253. doi: 10.1111/j.1600-0501.2012.02441.x

7. Tyndall, D. A., Price, J. B., Tetradis, S., Ganz, S. D., Hildebolt, C., \& Scarfe, W. C. (2012). Position statement of the American Academy of Oral and Maxillofacial Radiology on selection criteria for the use of radiology in dental implantology with emphasis on cone beam computed tomography. Oral Surg Oral Med Oral Pathol Oral Radiol, 113(6), 817-826. doi: 10.1016/j.oooo.2012.03.005.

8. Lang NP, Berglundh T. Periimplant diseases: where are we now? - Consensus of the Seventh European Workshop on Periodontology. J Clin Periodontol 2011: 38 : $178-181$. 
9. De Bruyn H, Vandeweghe S, Ruyffelaert C, Cosyn J, Sennerby L. Radiographic evaluation of modern oral implants with emphasis on crestal bone level and relevance to peri-implant health. Periodontol 2000. 2013 Jun;62(1):256-70.

10. Cooper LF, Raes F, Reside GJ, Garriga JS, Tarrida LG, Wiltfang J, Kern M, De Bruyn H. Comparison of radiographic and clinical outcomes following immediate provisionalization of single-tooth dental implants placed in healed alveolar ridges and extraction sockets. Int J Oral Maxillofac Implants 2010: 25: 1222-1232 


\section{CURRICULUM VITA}

J. Alec Power

College of Literature, Science and the Arts

University of Michigan (2012) with a B.S.

Major in Brain, Behavior, and Cognitive Science

Tutored dental students in four courses at the University of Louisville School of Dentistry (operative dentistry, removable partial dentistry, fixed partial dentistry, and complete dentures).

Leadership positioned in professional organizations:

Louisville Student American Dental Education Association (Treasurer)

Alpha Omega International Dental Fraternity (Community Service Chair)

Member:

Louisville Orthodontic Interest Group

The American Association of Dental Research

The American Student Dental Association

Hispanic Dental Association

DelphiSociety Award Winner (2017)

Presented at the American Dental Education Association National Conference (2017). 